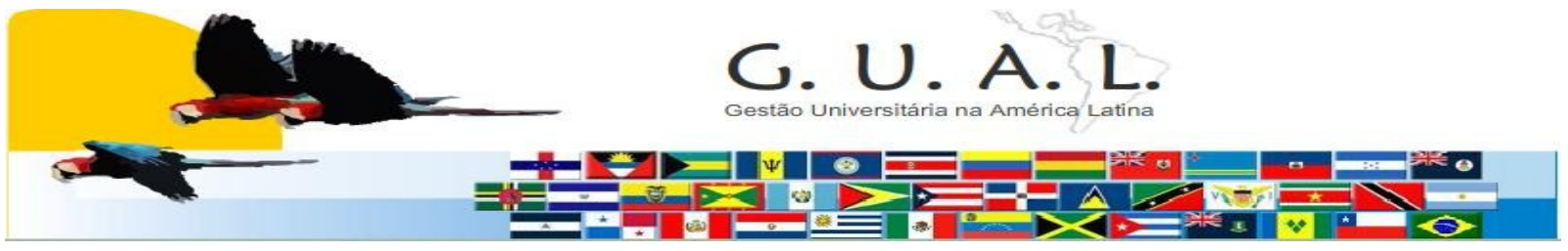

ISSN 1983-4535

\title{
AUTONOMIA DO ALUNO NA EDUCAÇÃO A DISTÂNCIA: O CASO DO CURSO DE ADMINISTRAÇÃO A DISTÂNCIA DA UFSC
}

\author{
Alessandra de Linhares Jacobsen, Doutora \\ Universidade Federal de Santa Catarina - UFSC \\ oajac@newsite.com.br
}

Maurício Fernandes Pereira, Doutor

Universidade Federal de Santa Catarina - UFSC

mpereira@cse.ufsc.br

Marcos Baptista Lopez Dalmau, Doutor

Universidade Federal de Santa Catarina - UFSC

dalmau@cse.ufsc.br

\author{
Rogério da Silva Nunes, Doutor \\ Universidade Federal de Santa Catarina - UFSC \\ rogerionunes@cse.ufsc.br
}

Rudimar Antunes da Rocha, Doutor

Universidade Federal de Santa Catarina - UFSC

rrudimar@cse.ufsc.br

\author{
Isaias Scalabrin Bianchi, Bacharel \\ Universidade Federal de Santa Catarina - UFSC
}

isaiasbianchi@hotmail.com

\section{RESUMO}

O presente artigo objetiva analisar como o Curso de Administração a Distância da Universidade Federal de Santa Catarina (UFSC) administra a autonomia conferida ao seu alunado em função das características inerentes a tal modalidade de ensino. Para tanto, faz uso de uma pesquisa qualitativa, bibliográfica, descritiva, e um estudo de caso, realizada entre outubro de 2010 e finalizada em junho de 2011. A amostra, não-probabilística escolhida por acessibilidade e tipicidade, é formada pelo Chefe de Departamento/CAD, Coordenador do Curso e 3 membros da Comissão de Planejamento, Organização e Funcionamento do curso. Pela entrevista não-estruturada e observação participante natural obtiveram-se os dados primários. O Curso apresenta resultados favoráveis na implementação da aprendizagem independente, porém fragilidades comportamentais e tecnológicas afetam a autonomia do aluno.

Palavras-chave: Autonomia do aluno. Educação a distancia. Gestão da educação. 


\section{AUTONOMIA DO ALUNO NA EDUCAÇÃO A DISTÂNCIA: O CASO DO CURSO DE ADMINISTRAÇÃO A DISTÂNCIA DA UFSC}

\section{INTRODUÇÃO}

Baseadas no fato de que a informação e o conhecimento constituem-se em fontes primordiais para a obtenção de vantagem competitiva, as organizações têm como desafio garantir a qualidade do desempenho profissional dos seus colaboradores, o que requer o empreendimento permanente de ações voltadas ao aprendizado contínuo. Não obstante esta ser uma exigência do mercado de trabalho, a realidade atual revela algumas contradições: se por um lado é preciso haver o aprendizado contínuo, como forma de obter não só a sobrevivência da organização como do próprio capital humano, solicitando, portanto, a realização de investimentos constantes em treinamento e qualificação, por outro há a impossibilidade de deslocamentos físicos freqüentes e massivos até as instituições de ensino convencionais.

Este quadro, marcado por alterações e situações antagônicas, reflete-se sobre as tradicionais formas de pensar e de promover o ensino, abrindo mais espaço aos sistemas alternativos, com destaque à educação a distância $(\mathrm{EaD})$, cujos conceitos de tempo e espaço são trabalhados de um modo todo particular.

Adicionalmente, verifica-se que, apesar da referida modalidade de ensino ser usada especialmente como alternativa de baixo-custo para desenvolver treinamento e aperfeiçoamento da força de trabalho, o surgimento cada vez mais intenso de programas a distância, inclusive em nível de graduação e de pós-graduação, reflete também um movimento mundial caracterizado pela busca crescente dos atrativos oferecidos para a continuidade dos estudos.

No Brasil, o quadro neste setor é igualmente representativo, havendo atualmente uma variedade de instituições de ensino brasileiras desenvolvendo programas dessa natureza, tal como a Universidade Federal de Santa Catarina (UFSC) que se iniciou nesse ramo por intermédio do Laboratório de Ensino a Distância (LED), criado oficialmente em 1995 por seu Programa de Pós-Graduação em Engenharia de Produção (PPGEP). No entanto, diante da forte demanda, não só por educação continuada como também por capacitação e aperfeiçoamento profissional, a UFSC permanece investindo na implementação de projetos a distância, a exemplo do Departamento de Ciências da Administração (CAD/UFSC), que passa a oferecer o seu primeiro Curso de Graduação em Administração a Distância a partir de 2006.

De fato, com o advento das modernas tecnologias de informação e de comunicação, 


\section{AUTONOMIA DO ALUNO NA EDUCAÇÃO A DISTÂNCIA: O CASO DO CURSO DE ADMINISTRAÇÃO A DISTÂNCIA DA UFSC}

sobretudo com a Internet, problemas relacionados à distância física e à falta de tempo ficam aparentemente solucionados, podendo-se conectar pessoas de toda parte do mundo em torno de um único projeto de educação. Além disso, a atual geração de educação a distância é marcada pela forte ênfase dada ao auto-aprendizado, possibilitando níveis superiores de autonomia aos alunos no desenvolvimento das atividades acadêmicas. A despeito de haver tantas facilidades e atrativos, a preocupação, entretanto, concentra-se em garantir a qualidade das atividades, mesmo a distância, considerando que tanto professores como alunos passam a atuar de modo totalmente diferenciado se comparado ao sistema presencial.

Diante desse cenário, o presente trabalho tem como objetivo analisar como o Curso de Graduação em Administração a Distância da UFSC administra a autonomia conferida ao seu alunado em função das características inerentes à tal modalidade de ensino. Com vistas a atingir o objetivo proposto, a estrutura do artigo é composta por, basicamente, 6 capítulos. Nos capítulos 2 e 3 faz-se uma reflexão teórica a respeito do assunto em questão. No capítulo 4, descreve-se o método escolhido para o desenvolvimento da pesquisa. Já, o capítulo 5 é destinado à apresentação e à análise do caso estudado, enquanto que no capítulo 6 são trazidas as conclusões obtidas.

\section{A ATUAL GERAÇÃO DE EDUCAÇÃO A DISTÂNCIA}

Muito embora a EaD esteja em voga, a sua história é marcada por uma extensa trajetória, destacando-se a incorporação progressiva de ferramentas tecnológicas cada mais potentes, especialmente no que se refere ao nível de interação permitido entre os atores do processo. A modalidade ora em questão não se refere, em verdade, nem a um conceito novo e nem tampouco a uma prática recente, como relatam os fatos históricos, tendo como fundamento básico o ensino que ocorre quando alunos e professores encontram-se separados, seja no tempo e/ou no espaço (MOORE, 2002).

No início, tal sistema educacional fazia uso intenso da mídia escrita. Ao passar dos tempos, no entanto, a EaD começa a mostrar um caráter bem mais dinâmico ao se apoiar, também, em tecnologias como o telefone, o rádio e a televisão. Mas seu processo evolutivo não pára por ai, sendo que atualmente os parâmetros de desempenho e de interação humana chamam muito mais atenção, assumindo a inclusão das vantagens oferecidas pelas novas tecnologias digitais e recursos das telecomunicações, primordialmente em termos dos 
simuladores on-line, em redes de computadores, avançando em direção da comunicação instantânea de dados vozimagem via satélite ou por cabos de fibra ótica, com aplicação de formas de grande interação entre o aluno e o centro produtor, quer utilizando-se de inteligência artificial - IA -, ou mesmo de comunicação instantânea com professores e monitores (NUNES, 2011, p.1).

Nesse contexto, o destaque fica por conta da Internet, a qual dispõe de inúmeras oportunidades para a educação a distância pela Web. Em complemento, há que se assinalar a atuação de determinados recursos, tais como a teleconferência e a videoconferência, os quais geram interessantes níveis de interatividade entre os atores do processo (professores, alunos e pessoal técnico).

Como sugere Corrêa (2011, p.3-4), tem-se 3 derivações desta modalidade educacional, quais sejam:

a) primeira geração (textual): desenvolvida até a década de 1960, esta geração é conhecida como ensino por correspondência;

b) segunda geração (analógica): caracterizada pelo uso da multimídia e de multimeios, em que tecnologias como a imprensa, o áudio, videocassetes e programas de computador eram combinadas dependendo das necessidades; e

c) terceira geração (digital): apresenta forte influência das tecnologias interativas em que aprendizes são conectados, síncrona ou assincronamente, por dispositivos capazes de simular uma sala de aula, isto é, através de áudio, de computadores, e de videoconferências, por exemplo.

Dessa forma, Belloni (2001, p.51) ressalta que a terceira geração, iniciada a partir dos anos 90, representa, sobretudo, uma proposta baseada na aplicação de variados meios, inclusive aqueles típicos das gerações anteriores, com forte tendência à diminuição do uso de materiais divulgados por intermédio dos meios de comunicação de massa (broadcasting ${ }^{\mathrm{i}}$ ) e a crescente utilização de materiais de uso pessoal (self media ${ }^{i i}$ ). Ainda, segundo a autora, a principal diferença entre as gerações de $\mathrm{EaD}$ reside no fato das duas primeiras possibilitarem nível inferior de interação entre o professores e alunos, "embora as experiências existentes, em grande maioria típicas da segunda geração de multimeios, ofereçam muitas vezes serviços de apoio aos estudantes" na forma de tutoria e aconselhamento por telefone e mesmo encontros presenciais" (BELLONI, 2001, p.51). 


\section{AUTONOMIA DO ALUNO NA EDUCAÇÃO A DISTÂNCIA: O CASO DO CURSO DE ADMINISTRAÇÃO A DISTÂNCIA DA UFSC}

Finalmente, a atual geração tem como característica a ênfase que dá ao autoaprendizado baseado em recursos digitais como suporte interativo. Assim, com a facilidade de acesso à estrutura, material instrucional e ao pessoal responsável pelo processo de ensinoaprendizagem, é disponibilizada ao aluno maior autonomia para o desenvolvimento das suas atividades acadêmicas.

\section{AUTONOMIA DO ALUNO NA EAD}

Sintonizada com as demandas da atual sociedade, Belloni (2001, p.103) aponta possíveis caminhos para a operacionalização de um processo educativo efetivamente centrado no estudante, considerado como um ser autônomo e não como um ente a ser protegido. Em contrapartida, sabe-se que a educação é, e sempre foi, um processo complexo que utiliza a mediação de algum tipo de meio de comunicação como complemento ou apoio à ação do professor em sua interação pessoal e direta com os estudantes.

No caso da $\mathrm{EaD}$, a interação com o professor é eminentemente indireta e tem de ser mediatizada por uma combinação dos mais adequados suportes técnicos de comunicação, o que torna esta modalidade bem mais dependente da mediatização que a educação convencional, de onde decorre a grande importância dos meios tecnológicos hoje disponíveis (BELLONI, 2001, p.54). A própria legislação brasileira, por meio do Decreto $N^{\circ} 5.622$, de 19 de dezembro de 2005, em seu Artigo $1^{\circ}$, caracteriza a EaD “como modalidade educacional na qual a mediação didático-pedagógica nos processos de ensino e aprendizagem ocorre com a utilização de meios e tecnologias de informação e comunicação, com estudantes e professores desenvolvendo atividades educativas em lugares e tempos diversos” (BRASIL, 2005).

É fato que na educação a distância o nível de autonomia conferido ao aluno é superior, se comparado à modalidade presencial, pois neste tipo de ambiente, o aluno passa a ser o principal gestor do próprio processo de aprendizagem. Por outro lado, o professor assume tanto o papel de orientador como de mediador. Tais ambientes exigem, desse modo, o pleno engajamento do aluno, reconhecendo-o como um indivíduo que tem potencial para ser um mestre de si mesmo em relação ao seu próprio destino. De acordo com este modelo, o professor torna-se o mentor do aluno, servindo como um consultor de conteúdos, motivador e integrador do contexto, assim como um gestor participante da experiência de aprendizado.

Authier (1998), sabiamente, alerta que, na $\mathrm{EaD}$, os professores acabam assumindo 


\section{AUTONOMIA DO ALUNO NA EDUCAÇÃO A DISTÂNCIA: O CASO DO CURSO DE ADMINISTRAÇÃO A DISTÂNCIA DA UFSC}

uma série de competências, sendo simultaneamente "produtores quando elaboram suas propostas de cursos; conselheiros, quando acompanham os alunos; parceiros, quando constroem com os especialistas em tecnologia abordagens inovadoras de aprendizagem".

Nesta dimensão, a autonomia do aluno é vista como "a medida pela qual, na relação ensino-aprendizagem, é o aluno e não o professor quem determina os objetivos, as experiências de aprendizagem e as decisões de avaliação do programa de aprendizagem" (MOORE, 2002). Trata-se, portanto, de um paradigma que extrapola alguns dos limites estabelecidos e já sedimentados na maioria dos programas de educação convencional. Por meio desta concepção, verifica-se que, em tese, na atual geração, a modalidade a distância, por suas características, acaba imprimindo no aluno um rol de poderes e de liberdade de decisão sobre a definição do seu futuro ao longo do processo de ensino-aprendizagem nunca antes experimentados.

Em contrapartida, o aluno tem igualmente tarefas a serem desempenhadas e, além disso, passa a se expor mais facilmente, pois, como afirma Kenski (2003, p.125), "sempre haverá tempo e espaço para apresentação de suas opiniões. E mais: será solicitado - pelo professor e pelos colegas - a se posicionar, dizer o que pensa, tomar partido", a qualquer instante. Concomitantemente, além de possuir maior autonomia em relação à definição do seu destino acadêmico, o aluno assume maior responsabilidade na condução dos seus estudos, devendo tomar muito mais decisões referentes ao seu futuro, se for comparado ao contexto da educação convencional.

Este cenário representa, pelo menos, uma mudança de cultura entre aqueles que pela primeira vez farão parte de um programa a distância. Como conseqüência, especialistas vêm, progressivamente, demonstrando interesse pelo assunto. Por exemplo, tanto Moore (2002) como Barreto (2011) sugerem que há uma forte relação entre a estrutura do programa, as mídias utilizadas e o nível de diálogo estabelecido entre os personagens do processo com o nível de autonomia disponível e/ou vivenciado pelo aluno. Sobre o assunto, Moore (2002, p.2) assinala uma das primeiras tentativas de teorizar sobre $\mathrm{EaD}$, por volta de 1972, originando a denominada Teoria da Distância Transacional, como segue:

Apesar de a teoria apresentada destacar a relação professor-aluno, não se pode esquecer que o espaço de comunicação criado pela distância transacional diz respeito também aos demais participantes do processo de ensino-aprendizagem. Neste contexto, vale lembrar o 


\title{
AUTONOMIA DO ALUNO NA EDUCAÇÃO A DISTÂNCIA: O CASO DO CURSO DE ADMINISTRAÇÃO A DISTÂNCIA DA UFSC
}

conceito original de transação, apresentado, em 1949, por Dewey (apud MOORE, 2002): “ele denota a interação entre o ambiente, os indivíduos e os padrões de comportamento numa dada situação".

\begin{abstract}
Nesta primeira teoria afirma-se que a Educação a Distância não é uma simples separação geográfica entre alunos e professores, mas sim, e mais importante, trata-se de um conceito pedagógico. É um conceito que descreve o universo de relações professor-aluno que se dão quando alunos e instrutores estão separados no espaço e/ou no tempo. Este universo de relações pode ser ordenado segundo uma tipologia construída em torno dos componentes mais elementares deste campo, a estrutura dos programas educacionais, a interação entre alunos e professores, e a natureza e o grau de autonomia do aluno (MOORE, 2002, p.2).
\end{abstract}

Assim, no que tange à educação a distância, a transação ocorre entre os atores do processo em um ambiente cuja principal característica é justamente a separação entre esses sujeitos, o que afeta definitivamente tanto o ensino quanto a aprendizagem. Pois, como afirma Moore (2002), com a separação, “surge um espaço psicológico e comunicacional a ser transposto, um espaço de potenciais mal-entendidos entre as intervenções do instrutor e as do aluno". Tal espaço, chamado de distância transacional, apresenta graus distintos de intensidade em ambientes de aprendizagem, dependendo de como é afetado por determinados fatores relacionados à estrutura do curso, à tecnologia usada e à comunicação estabelecida.

Resgatando, portanto, o conceito de distância transacional, nota-se que quanto maior for esta distância, maior deverá ser a autonomia exercida pelo aluno, o que em muitos casos é salutar, já em outros representa um problema, posto que não se tem o devido equilíbrio entre as variáveis estrutura, tecnologia e diálogo.

Simultaneamente, o papel do professor/instrutor e as interfaces que estabelece com alunos, conteúdos e demais elementos integrantes de um ambiente de educação a distância têm forte influência sobre o sucesso do programa. Como lembra Belloni (2001, p.81), nesse novo contexto, "o professor deverá tornar-se parceiro dos estudantes no processo de ensinoaprendizagem". Destacando-se, conseqüentemente, os papéis exercidos pelo professor-autor e pelo tutor.

\subsection{O professor diante da autonomia discente}

De acordo com Barreto (2011, p.1-2), se por um lado, o professor-autor deve fazer 


\section{AUTONOMIA DO ALUNO NA EDUCAÇÃO A DISTÂNCIA: O CASO DO CURSO DE ADMINISTRAÇÃO A DISTÂNCIA DA UFSC}

um recorte do conhecimento em determinada área do saber que ele domina e, sob algumas condições tecno-metodológicas, apresentá-lo aos alunos; por outro, o tutor deve "mediar a relação/interação educativa estabelecida entre o aluno e o conteúdo a ele apresentado, entre o aluno e professor e entre o aluno e outros alunos".

É justamente a partir dos feedbacks oriundos das relações estabelecidas com professores, isto é, dos diálogos desenvolvidos, é que são geradas alterações, buscando-se o refinamento de determinadas características apresentadas por um programa de $\mathrm{EaD}$, incluindo o nível de autonomia dos alunos. A falta de imediatez de respostas às dúvidas e anseios dos alunos é considerada uma dificuldade comum a qualquer modalidade educacional. Porém, lidar individualmente com cada aluno a distância e, ao mesmo tempo, promover e ajudá-lo a construir a sua autonomia é um desafio realmente significativo, residindo, aqui, um diferencial entre os dois tipos de educação - convencional e presencial.

Há que se realçar, também, o papel de autoridade do professor no cenário da EaD. Segundo Moore (1994, p.1), já que os alunos tradicionalmente costumam se encontrar sob o mesmo ambiente do professor, o principal problema do sistema a distância tornou-se como controlá-los adequadamente. Para tanto, a perspectiva relacionada a símbolos permite maiores reflexões sobre fontes de poder, como sugere Morgan (1996, p.182), em sua obra. Para o autor, o poder

reside na habilidade que tem uma pessoa para persuadir os demais a idealizar realidades que sejam mais interessantes para alguém perseguir. Liderança, em última análise, envolve a habilidade de definir a realidade aos seus subordinados, a influência de líderes mais democráticos permite que as definições de uma situação surjam a partir dos pontos de vista dos outros. A influência do líder democrático é, de longe, muito mais sutil e simbólica. (...) Administrando os sentidos ligados à situação, o líder, na verdade, utiliza uma forma de poder simbólico que exerce influência decisiva sobre a maneira pela qual as pessoas percebem a sua realidade e, conseqüentemente, sobre a maneira de agir (MORGAN, 1996, p.182).

Em complemento, Morgan (1996, p.163) aponta o poder como o "meio através do qual conflitos de interesse são, afinal, resolvidos". O professor deve desenvolver, portanto, habilidade de influenciar e conduzir os alunos a agirem em prol da sua aprendizagem. A verdade é que, independentemente da denominação apresentada ao personagem professor, instrutor, ou até tutor e, mais ainda, seja qual for a modalidade de educação (a distância ou convencional-presencial), "é no professor que situamos a principal mediação na relação 


\section{AUTONOMIA DO ALUNO NA EDUCAÇÃO A DISTÂNCIA: O CASO DO CURSO DE ADMINISTRAÇÃO A DISTÂNCIA DA UFSC}

pedagógica e é esta vertente que direciona nosso compromisso com sua competência" (RIBEIRO; BREGUNCI, 1986. p.10).

Como mostra Belloni (2001, p.82), a EaD caracteriza-se por ser um processo complexo multifacetado, que inclui muitas pessoas, todas podendo reinvidicar sua contribuição ao ensino. Assim, em oposição ao sistema convencional de educação, fica difícil afirmar quem realmente detém o título de professor em ambientes a distância, atribuindo-se a tal profissional uma série de novas funções que nem sempre são exercidas pela mesma pessoa e tampouco ocorrem necessariamente na mesma experiência educacional.

Desse modo, a autora acaba por agrupar as funções docentes em 3 (três) grandes categorias, a saber: a primeira engloba aqueles responsáveis pela concepção e realização dos cursos e materiais; a segunda refere-se aos docentes que asseguram o planejamento e organização da distribuição de materiais e da administração acadêmica (matrícula e avaliação); e a terceira diz respeito àqueles responsáveis pelo acompanhamento do estudante durante o processo de aprendizagem (tutoria, aconselhamento e apoio psicológico e avaliação) (BELLONI, 2001, p.84).

Em suma, o educador, isto é o professor, precisa ter uma habilidade específica diante da autonomia vivida pelo aluno de programas a distância, inclusive devendo levar em conta aspectos comportamentais e psicológicos. Reflexões de Barreto (2011), acerca do trabalho de Moore (2002), sugerem que a autonomia do aluno que aprende a distância é mais dificilmente construída, sobretudo quando se trata de adultos, cujo nível de resistência às inovações, em geral, é maior se comparado ao público infantil. Quanto ao assunto, Knowles (1970 apud MOORE, 1994) comenta que "adultos em via de regra não estão preparados para uma aprendizagem independente; precisam atravessar um processo de reorientação para aprenderem como adultos". Igualmente interessante fazem-se as observações de Ribeiro e Bregunci (1986, p.15-16) sobre o comportamento dos adultos em programas de ensino/aprendizagem:

(...) depois de cerca de 12 anos de escolaridade ele provavelmente será bastante dependente. Ele esperará que os professores lhe digam o que fazer, como fazer, quando concluir e, ainda por cima, dizendo-lhe quão eficiente é seu desempenho.

Por outro lado, os adultos são reconhecidamente alunos com maior capacidade de 


\section{AUTONOMIA DO ALUNO NA EDUCAÇÃO A DISTÂNCIA: O CASO DO CURSO DE ADMINISTRAÇÃO A DISTÂNCIA DA UFSC}

motivação para os estudos, além de apresentarem grandes habilidades para estudar e desenvolver disciplina. Um dos grandes desafios presentes na EaD está, portanto, relacionado diretamente à autonomia exigida no contexto escola. Pois, para que os alunos possam fazer uso eficaz dessa liberdade acadêmica, é preciso estabelecer em projetos a distância estratégias que reduzam o nível de resistência em relação à tal inovação, capacitando-os e os estimulando a usá-la adequadamente.

Diante desse cenário, é decisiva a atuação do mediador do processo, por intermédio da figura do professor, do instrutor e/ou do monitor, cuja maior dificuldade constitui-se na identificação e manipulação dos significados e símbolos gerados durante as interações. Ao longo dos contatos estabelecidos para se efetuarem mediações no âmbito da educação a distância, porém, o referido mediador deve dispor também da habilidade de gerenciar os significados, usando o simbolismo como uma promissora fonte de informação e de poder.

Nesse sentido, identificam-se, em imagens e símbolos, ferramentas que podem ser usadas na administração dos sentidos e, portanto, para delinear relações de poder no ambiente educacional. Adicionalmente, cabe lembrar que, de fato, tem-se aí o grande facilitador do processo, posto que o centro da questão não é o software nem o hardaware, como grande parte dos programas a distância erroneamente entendem. Mas sim, o peopleware, ou seja, as pessoas e as relações estabelecidas entre elas.

Finalmente, ressalta-se que em ambientes de educação a distância, sobretudo aqueles baseados em computador, "não existe um chefe, um professor ou detentor permanente do saber, mas uma circularidade de informações e trocas visando ao alcance de objetivos que podem ser de todo o grupo ou apenas de um número restrito de pessoas ou até mesmo de uma única pessoa” (KENSKI, 2003, p.113).

De outro modo, não é recomendável dar mais destaque a um sujeito do que a outro. Todos os atores desta modalidade educacional - professores, alunos e demais colaboradores desempenham papéis igualmente relevantes na construção do conhecimento e no alcance dos objetivos propostos, sendo responsáveis pelas contribuições que possam dar para a soma e, conseqüente, constituição do todo.

Em verdade, professores precisam ser competentes não só para preparar material instrucional adequado, mas especialmente, para motivar o aluno e para conduzir processos interativos que contribuam na construção do seu conhecimento. Já o aluno, apesar de ter

Rev. GUAL., Florianópolis, v.4, n. 2, p.53-73, mai/ago. 2011 


\section{AUTONOMIA DO ALUNO NA EDUCAÇÃO A DISTÂNCIA: O CASO DO CURSO DE ADMINISTRAÇÃO A DISTÂNCIA DA UFSC}

maior autonomia na condução dos seus estudos, também precisa assumir maior responsabilidade em relação aos resultados alcançados.

\section{PROCEDIMENTOS METODOLÓGICOS}

A metodologia adotada para o desenvolvimento deste trabalho segue a classificação sugerida por Vergara (1997). A partir do que confere a obra dessa autora, é possível classificar a presente pesquisa como sendo qualitativa, tendo como meios para a sua implementação a pesquisa bibliográfica e o estudo de caso. Assim, o caso estudado refere-se ao Curso de Graduação em Administração a Distância da UFSC, criado em 2006. Já, quanto aos fins, trata-se de uma pesquisa descritiva realizada em uma perspectiva transversal, sendo iniciada em outubro de 2010 e finalizada em junho de 2011.

A população-alvo é composta pelo Chefe do Departamento de Ciências da Administração da UFSC, pelo Coordenador do Curso de Graduação em Ciências da Administração e pelos 9 membros que integram a Comissão de Planejamento, Organização e Funcionamento do referido Curso (PORTAL CAD, 2011). A amostra não-probabilística foi escolhida, basicamente, pelos critérios de acessibilidade e tipicidade, sendo constituída pelo Chefe de Departamento, pelo Coordenador do Curso e por 3 membros da Comissão supra citada.

Inicialmente, fez-se o levantamento bibliográfico para a obtenção dos dados secundários, com destaque à consulta de obras sobre educação a distância, distância transacional, processo interativo e autonomia na educação. Em seguida, os instrumentos de coleta dos dados primários foram a entrevista não-estruturada (junto aos elementos da amostra) e a observação participante natural, posto que todos os professores pesquisadores deste trabalho integram o corpo docente do aludido curso. Vale ressaltar que os resultados obtidos por meio da pesquisa limitam-se ao caso analisado, tendo como escopo do estudo os temas anteriormente mencionados dentro dos limites da ciência administrativa, não se expandindo a aspectos pedagógicos do processo de ensino e aprendizagem.

\section{APRESENTAÇÃO E ANÁLISE DO CASO}

Considerando-se o objetivo pretendido para esta pesquisa, faz-se aqui a apresentação e análise dos dados coletados, por meio de 2 seções. A primeira destina-se à caracterização do 


\section{AUTONOMIA DO ALUNO NA EDUCAÇÃO A DISTÂNCIA: O CASO DO CURSO DE ADMINISTRAÇÃO A DISTÂNCIA DA UFSC}

Curso de Graduação em Administração a Distância da UFSC. Já, na segunda seção, analisa-se como o referido Curso lida com o nível de autonomia conferido ao aluno para a gestão do seu próprio processo de aprendizagem.

\subsection{Caracterização do Curso em Administração a Distância da UFSC}

Em relação ao Brasil, país caracteristicamente extenso e com relativas dificuldades socioeconômicas, o sistema de educação a distância tem se mostrado como uma alternativa particularmente atraente. Nesse campo, o marco inicial ocorre com a criação do Instituto Rádio Motor, em 1939, e com o Instituto Universal Brasileiro, instituído em 1941. Ambos oferecem, até hoje, cursos profissionalizantes com base em folhetos impressos. Da mesma forma, os anos 70 presenciaram valiosas iniciativas, como a da Fundação Roberto Marinho ao viabilizar educação supletiva a distância para primeiro e segundo graus, apoiando-se em recursos como o rádio, TV e material impresso. Nas décadas subseqüentes, no entanto, não houve muito progresso na área, especialmente em decorrência de motivos tais como a descontinuidade de projetos, a falta de memória administrativa pública brasileira e o receio em adotar procedimentos rigorosos e científicos de avaliação de propostas e de programas em curso, conforme confessa Nunes $(2011$, p.8).

Preocupado com tais questões, o governo brasileiro vem se empenhando no desenvolvimento e incentivo de programas de $\mathrm{EaD}$ no país nas suas mais diferentes versões, como deixa transparecer uma comissão de especialistas designada pelo próprio Ministério da Educação (MEC) ${ }^{\text {iii }}$ para apoiá-lo nesse sentido, conforme se constata a seguir:

É preocupação do Ministério da Educação e da sociedade como um todo que esse processo de incorporação de novos recursos e possibilidades, aliado à ampliação da oferta, aconteça de forma tal que não apenas restem preservados os melhores padrões de qualidade já atingidos pela educação tradicional, mas que também eles sejam aperfeiçoados. Neste sentido, a incorporação de tecnologias e metodologias precisa conduzir a ofertas que atendam aos mesmos padrões de qualidade, independentemente da combinação de recursos presenciais, virtuais ou a distância, (...) (BRASIL, 2002, p.6).

Diante dos esforços governamentais, a expectativa é que haja modificações em tal cenário a partir da consolidação de um importante empreendimento, a Universidade Aberta do Brasil (UAB), projeto criado pelo $\mathrm{MEC}$, em 2005, para a articulação e integração 


\section{AUTONOMIA DO ALUNO NA EDUCAÇÃO A DISTÂNCIA: O CASO DO CURSO DE ADMINISTRAÇÃO A DISTÂNCIA DA UFSC}

experimental de um sistema nacional de educação superior. Insere-se nesta iniciativa, o Curso de Graduação em Administração a Distância da Universidade Federal de Santa Catarina, criado no dia 10 de julho de 2006, como resultado de uma parceria firmada entre o Banco do Brasil e MEC (via Secretaria de Educação a Distância) e instituições federais e estaduais de ensino superior. Nesse sentido, seu público alvo é formado por funcionários do Banco do Brasil, servidores da UFSC e outros servidores públicos, tendo em Santa Catarina o total de 611 alunos distribuídos em pólos de ensino situados em 10 cidades do Estado, quais sejam: Laguna, Joinville, Palhoça, Tubarão, Criciúma, Chapecó, Canoinhas, Araranguá, Lages e Florianópolis.

Trata-se de um projeto piloto com duração de quatro anos e meio e carga-horária de 3.000 horas/aula, que apresenta como objetivo geral formar o profissional administrador com capacidade para atuar na micro, pequena e média empresa, dotado de habilidade empreendedora, analítica para elaborar diagnósticos, preparado para propor mudanças, que desenvolva uma visão sistêmica e que conduza, dentro da ética, as empresas a atender as necessidades da sociedade. Assim, os Cursos oferecidos pelas universidades consorciadas estão inseridos dentro do sistema semipresencial (mínimo de $30 \%$ de aulas presenciais do total da carga horária), sendo que seus 3 primeiros anos foram estruturados em uma base de conhecimento comum e ficando o tempo restante destinado a diferentes ênfases, o que deve ser definido pela instituição ofertante.

No caso específico do Curso de Administração a Distância da UFSC, cada disciplina adota uma estrutura previamente discutida, seguindo com o delineamento de um cronograma. A partir da definição da base de funcionamento da disciplina e do seu cronograma, é solicitado aos alunos o desenvolvimento de uma série de atividades de aprendizagem devidamente pontuadas para efeitos de avaliação, quais sejam: Fórum, Lista de Discussão, Chat, Lista de Exercícios, Plano de Estudo e Exercícios sobre o tema da Videoconferência. Durante o planejamento da disciplina, a priori, é feita uma análise da pertinência de cada atividade ao seu conteúdo. Por isso, as disciplinas apresentam especificidades distintas entre si em relação ao seu conjunto de atividades. Finalmente, tem-se a Prova Presencial, realizada em cada pólo de ensino.

Diante dessas características, analisa-se, em seguida, como se administra a autonomia do aluno no Curso de Administração a Distância da UFSC.

Rev. GUAL., Florianópolis, v.4, n. 2, p.53-73, mai/ago. 2011 


\section{AUTONOMIA DO ALUNO NA EDUCAÇÃO A DISTÂNCIA: O CASO DO CURSO DE ADMINISTRAÇÃO A DISTÂNCIA DA UFSC}

\subsection{Lidando com a autonomia do aluno}

Os dados coletados para esta pesquisa demonstraram algumas interessantes coincidências e discrepâncias em relação à teoria estudada. Inicialmente, pode-se afirmar que a procura pelo Curso pesquisado segue a tendência do mercado. Pois, especialmente aqueles que residem fora de Florianópolis (onde se encontra o maior campus UFSC) detectaram, no projeto, a grande facilidade de acesso a um curso público e gratuito, oferecido por uma universidade federal brasileira. Já, quanto ao Banco do Brasil, trata-se da instituição que, percebendo os benefícios da $\mathrm{EaD}$, parte para a realização de investimentos na qualificação do seu pessoal, já que se trata de uma alternativa de baixo-custo com capacidade para solucionar dificuldades inerentes a ter que dispensar funcionários das suas atividades diárias para que possam estudar ou ter que arcar com custos relativos a deslocamentos freqüentes até instituições de ensino convencionais. Tal realidade tem, de fato, servido de estímulo aos participantes.

Ainda, seguindo a categorização apresentada por Corrêa (2011), classifica-se o Curso como sendo de $3^{\mathrm{a}}$ geração, uma vez que está baseado na aplicação de uma gama de meios, indo desde o uso de material impresso (na forma de apostilas), como principal material instrucional de apoio, até o emprego de tecnologias mais interativas, tais como o fax, telefone e Internet para receber dúvidas e atividades e para se comunicar e dar feedback aos alunos. O chamado Ambiente Virtual de Ensino-Aprendizagem (AVEA), software que permite o acesso do aluno a mensagens e conteúdos armazenados em bancos de dados digitais, é um importante meio de interação entre os atores do processo, e está sendo bastante usado. Porém, esta destacada ferramenta ainda exibe alguns entraves, tanto para alunos como para professores, e equipe técnica, primordialmente em função de limitações operacionais, tais como dificuldades em navegar, fazer downloads e anexar material. Segundo os entrevistados, apesar de já existir experiência acumulada na manipulação da referida ferramenta, esta apresenta o maior índice de rejeição por parte do alunado.

Por último, ressalta-se a videoconferência, tecnologia que viabiliza a interação síncrona, face-a-face, entre professores e alunos, além de constituir a principal oportunidade de contato entre alunos. Sobretudo porque os alunos reúnem-se em sala de aula para participar das videoconferências, além de poder fazê-lo também por meio de um computador conectado na Internet. Assim, é através das videoconferências que efetivamente o docente tem a chance 


\section{AUTONOMIA DO ALUNO NA EDUCAÇÃO A DISTÂNCIA: O CASO DO CURSO DE ADMINISTRAÇÃO A DISTÂNCIA DA UFSC}

de estabelecer um diálogo direto com seus alunos, agindo primordialmente como um consultor de conteúdos, motivador e integrador do contexto. Os relatos obtidos revelam um elevado nível de satisfação por parte dos alunos em relação às aulas baseadas em videoconferência. Apesar disso, os responsáveis pelo Curso ainda não conseguiram sanar totalmente os problemas relativos à qualidade de áudio e de vídeo das videoconferências, sugerindo certo grau de intensidade na chamada distância transacional entre alunos e academia.

Tomando a opinião de especialistas, no Curso de Administração a Distância da UFSC, o aluno é, desde o início, e em cada disciplina, estimulado a ser o principal gestor do seu processo de aprendizagem. A teoria afirma categoricamente que, em oposição à educação convencional, em que o processo de ensino-aprendizagem está centrado no professor, no sistema a distância há que se permitir o pleno engajamento do aluno, reconhecendo-o como um indivíduo que tem potencial para comandar o seu futuro. Entretanto, a experiência corrente manifesta a necessidade de se fixarem limites claros em termos de atividades acadêmicas e prazos a serem cumpridos. Assim, baseando-se em cronogramas, os alunos assumem a responsabilidade de se organizarem para que possam atingir seus objetivos.

Outro instrumento que também opera de modo eficiente para que o aluno possa fazer uso adequado da sua autonomia é o Plano de Estudo, que se constitui em uma atividade a ser desenvolvida pelo próprio aluno no início de cada disciplina, a partir do cronograma que lhe é apresentado. Além de ser útil para que o discente possa se organizar, o Plano de Estudo serve ainda como uma ferramenta de controle e acompanhamento para a estrutura acadêmica de modo geral.

Adicionalmente, como na $\mathrm{EaD}$ a interação com o professor é indireta e tem de ser mediatizada por uma combinação de pessoas e tecnologias, observa-se relativa dependência da qualidade do material instrucional (apostilas e material complementar) e da atuação dos tutores, os quais intermediam as ações do professor no sentido de resolver dúvidas, estimular e, também, cobrar a participação do corpo discente naquilo que foi planejado por ele através do seu Plano de Estudo particular. A rapidez das respostas e a agilidade nos diálogos fixados, fatores determinantes para manter o aluno atento e motivado, obtiveram altos índices de satisfação pelos alunos. De modo geral, a amostra pesquisada (chefe de departamento, coordenador e membros da Comissão de Planejamento, Organização e Funcionamento do 


\section{AUTONOMIA DO ALUNO NA EDUCAÇÃO A DISTÂNCIA: O CASO DO CURSO DE ADMINISTRAÇÃO A DISTÂNCIA DA UFSC}

Curso), foi enfática em salientar o alto nível de profissionalismo da tutoria, muito embora reconheçam dificuldades inerentes a estimular o alunado, o que talvez exija treinamentos mais intensos no desenvolvimento da habilidade motivacional.

Em contrapartida, os pesquisados relatam que alguns professores manifestam a vontade em acompanhar mais de perto a atuação dos seus alunos e tutores. Pois, ainda não é possível observar, a distância, de modo síncrono e por meio do Ambiente Virtual de Aprendizagem, todas as perguntas feitas pelos alunos e respectivas respostas dadas pelos tutores. Diante do exposto, lembrando a classificação proposta por Authier (1998), no Curso analisado, o referido profissional assume com mais intensidade o papel de produtor de conteúdo e de parceiro da equipe técnica, em detrimento do papel de conselheiro, realizado, em primeira instância, pelos próprios tutores. Esse fato acaba dificultando a atuação docente em lidar individualmente, e de modo personalizado, com cada aluno a distância e, conseqüentemente, gerando entraves na escolha e aplicação dos recursos adequados para conduzir o aluno a agir em prol da sua aprendizagem, quando isso não está efetivamente acontecendo.

Enfim, observa-se como forte limitador certa resistência, tanto por parte do aluno como do professor, em participar das atividades que envolvam o uso intenso de tecnologias digitais. Tal comportamento acabou exigindo da coordenação do Curso a atribuição de notas de participação aos alunos para tudo que é solicitado, como meio de cobrança e de controle de desempenho. Os entrevistados dizem que, em geral, docentes e discentes aguardam diretrizes sobre o que deve ser feito e quando deve ser feito e, que, de modo geral, alunos que não executam suas tarefas apresentam certa dificuldade em assumir todas as responsabilidades colocadas justamente pelo aumento da autonomia conferida pela EaD. Essa talvez seja a principal justificativa para dados relativos à uma das primeiras disciplinas avaliadas, em que $20 \%$ dos alunos reprovados não realizaram as atividades de aprendizagem solicitadas, contra $0 \%$ da disciplina anterior.

Diante desse cenário, percebe-se a necessidade de se realizar um trabalho mais intenso na mudança da cultura organizacional e do modelo mental dos envolvidos, posto que a maioria nunca havia atuado em contexto que diferisse do presencial. Há que se continuar investindo na reorientação do público para que esse tenha condições de aprender plenamente como aprender a distância. Entende-se, assim, que apesar de já ter ocorrido antes do início do 


\section{AUTONOMIA DO ALUNO NA EDUCAÇÃO A DISTÂNCIA: O CASO DO CURSO DE ADMINISTRAÇÃO A DISTÂNCIA DA UFSC}

Curso, uma ampla divulgação e um constante treinamento sobre as características e adversidades dessa modalidade educacional, certamente, contribuirão para reduzir os níveis de resistência detectados, além da possibilidade de se usufruir melhor das vantagens da aprendizagem independente. Afinal, só se tem medo daquilo que não se conhece.

\section{CONCLUSÕES}

Como dizia Demo (2003, p.8), visto que "aprender é função da vida toda, é preciso encontrar a maneira de todos poderem, a vida toda, estudar". Nestes termos, em todos os níveis de ensino, a educação a distância passa a ser vista uma alternativa de grande valor e de baixo custo para a formação do indivíduo, especialmente em um período em que o capital intelectual das organizações é compreendido como um recurso fundamental para a obtenção de vantagens competitivas. Adicionalmente, a EaD, por suas características, permite transpor obstáculos financeiros, geográficos e de tempo impostos ao homem moderno que deseja aprender. Diante dessas promessas, é fundamental a instalação de uma cultura voltada ao atendimento das necessidades específicas de cada indivíduo ao longo do processo de ensinoaprendizagem e não, simplesmente, copiar e repetir tudo aquilo que já existe no âmbito da educação presencial, sempre resguardando os direitos do cidadão quanto à existência de padrões mínimos de qualidade. Insere-se, neste contexto, o Curso de Administração a Distância da UFSC, projeto resultante de uma parceria estabelecida entre Banco do Brasil, MEC e instituições federais e estaduais de ensino superior, que atende, desde julho de 2006, 611 alunos espalhados pelo Estado de Santa Catarina.

No que tange ao tema estudado, autonomia vivida pelo aluno, no aludido Curso observam-se tanto pontos fortes como ameaças a serem solucionadas. Os tutores, por exemplo, têm desempenhado um relevante papel como mediador das relações entre professor e aluno, especialmente no que diz respeito a garantir grande velocidade de resposta às suas necessidades. A variedade de recursos disponíveis para fixar o diálogo entre os atores do processo também chama a atenção, incluindo desde apostilas até meios de comunicação digitais. Entretanto, há que se garantir a qualidade tecnológica, evitando-se ruídos ao longo dos processos de comunicação e, ainda, a promoção de alterações no modelo mental de alguns dos envolvidos, com vistas a reduzir os níveis de resistência detectados.

Rev. GUAL., Florianópolis, v.4, n. 2, p.53-73, mai/ago. 2011 


\section{AUTONOMIA DO ALUNO NA EDUCAÇÃO A DISTÂNCIA: O CASO DO CURSO DE ADMINISTRAÇÃO A DISTÂNCIA DA UFSC}

Constatou-se todo o esforço por parte da coordenação do Curso em garantir e estimular graus elevados de autonomia para seus alunos no desempenho das atividades de aprendizagem. Eles próprios podem definir, por meio do seu Plano de Estudo, como farão uso do tempo e do conteúdo relativos a cada disciplina. Por esse motivo, é instituído, no início de cada disciplina, um cronograma de atividades que deve ser seguido. Por outro lado, tal instrumento, de certo modo, acaba engessando, no tempo, esse mesmo aluno. Concomitantemente, identifica-se certa dificuldade por parte dos reprovados em assumir as responsabilidades resultantes da autonomia alcançada.

Conclui-se, ainda sobre a urgência em se trabalhar o papel do professor ao longo do programa, pois, como efeito dessa autonomia, tal profissional acaba tendo que assumir uma postura diferenciada, devendo estar também preparado para lidar com os desafios trazidos por tal liberdade, detectando e respondendo com imediatez às dúvidas dos seus alunos e, sobretudo, desenvolvendo a habilidade e tendo independência para escolher adequadamente as fontes de poder disponíveis para que possa influenciá-los, acompanhar e controlar o seu desempenho, mesmo a distância. A aplicação de estruturas de controle e avaliação pelos docentes não deve se limitar ao alunado, mas precisa se expandir às demais dimensões, sobretudo no contexto dos tutores, para que o próprio educador tenha condições de diagnosticar, a tempo, falhas de comunicação e de conhecimento daqueles que estabelecem uma relação mais direta com o aluno.

A independência do aluno precisa ser exercida de maneira adequada, de tal forma que permita a perfeita gestão do espaço de comunicação criado pela distância transacional existente entre alunos, professores e técnicos. Por outro lado, apesar de haver uma série de iniciativas no sentido de garantir ao aluno o seu direito em se tornar o gestor do seu próprio destino, percebe-se adicionalmente a necessidade de se investir mais intensamente no desenvolvimento de ações voltadas a melhora na estrutura do curso, especialmente no âmbito tecnológico, que tem afetado inclusive a perfeita interação entre alunos professores através das videoconferências, prejudicando a motivação do alunado. Ou seja, apesar do forte apoio governamental e do crescente ganho de experiência e resultados positivos já atingidos pelo Curso de Administração a Distância da UFSC, os dados pesquisados mostram que o referido projeto ainda não alcançou plenamente o devido equilíbrio entre a variável estrutura, tecnologia e diálogo. 
O Curso analisado acredita no potencial que os alunos possuem em ser definitivamente um mestre de si mesmos. Porém, É preciso mais do que isso, há que se estar preparado para aprender e para ensinar a distância, abandonando todas as antigas crenças a respeito do que seja o processo de ensino-aprendizagem: esse é o desafio para todos aqueles que, pela primeira vez, vivem essa experiência. Trata-se, em verdade, de uma luta constante pela garantia da qualidade da educação, também nessa modalidade diferenciada.

\section{REFERÊNCIAS}

AUTHIER, M. Le bel avenir du parent pauvre. In Apprendre à distance. Le Monde de L'Éducation, de la Culture et de la Formation. France, Set. 1998.

BELLONI, M. L.. Educação a distância. Campinas, SP: Autores Associados, 2001.

BARRETO, L. S. A teoria da distância transacional, a autonomia do aluno e o papel do professor na perspectiva de Moore: um breve comentário. Revista Brasileira de

Aprendizagem Aberta e a Distância, v.1, n.2, dez. 2002. Disponível em:

$<$ http://www.abed.org.br/revistacientifica/_English/cartas_editor/documentos/teoria_distancia $. \mathrm{htm}>$. Acesso em: 14 maio 2011.

BRASIL. Ministério da Educação. Relatório da Comissão Assessora para Educação Superior a Distância. Brasília, DF, 2002. 40 p. $\overline{\mathrm{DF}, 2005 .}$

. Presidência da República. Decreto No 5.622, de 19 de dezembro de 2005. Brasília,

CORRÊA, F.P.P. Educação a distância e sua evolução. Disponível em:

$<$ http://www.pucsp.br/ cimid/7edu/poliseli/edudist.htm>. Acesso em: 01 jul. 2011.

DEMO, P. A tecnologia na educação e na aprendizagem. Disponível em

$<$ http://www.edutec.net/Textos/Alia/MISC/pdemo.htm>. Acesso em: 18 mar. 2003.

KENSKI, V. M. Tecnologias e ensino presencial e a distância. Campinas, SP: Papirus, 2003.

MOORE, M. Autonomy and interdependence. The American Journal of Distance Education. v.8, n.2, 1994.

. Teoria da distância transacional. Tradução: Wilson Azevedo. Revisão de tradução: José Manuel da Silva. Revista Brasileira de Aprendizagem Aberta e a Distância, v.1, n.1, jul. 2002.

MORGAN, G. Imagens da organização. São Paulo: Atlas, 1996. 
NUNES, I. B. Noções de educação a distância. Revista Educação a Distância, v.5, n.4, dez./93-abr./94. Brasília: Instituto Nacional de Educação a Distância, p. 7-25. Disponível em: $<$ http://www.rau-tu.unicamp.br/nou-rau/ead/document/?code=3>. Acesso em: 01 jul. 2011.

PORTAL CAD. Curso de Graduação em Administração: modalidade a distância. Disponível em: <portal.cad.ufsc.br/a-distância/>. Acesso em: mar. 2011.

RIBEIRO, L. C.; BREGUNCI, M. G.C. Interação em sala de aula: questões conceituais e metodológicas. Belo Horizonte: UFMG, 1986.

VERGARA, S. H. Projetos e relatórios de pesquisa em administração. São Paulo: Atlas, 1997.

\footnotetext{
${ }^{\text {i }}$ Broadcasting: programas de vídeo e de áudio, difundidos via antena (broadcasting) (BELLONI, 2001, p.50).

ii Self media: fitas cassetes, CD-ROMs, disquetes.

iii Trata-se da Comissão Assessora para Educação Superior a Distância, que foi designada pelo MEC através das Portarias $n^{\circ} 335$, de 06/02/2002, no 698 , de 12/03/2002, e no 1.786 , de 20/06/2002.
} 


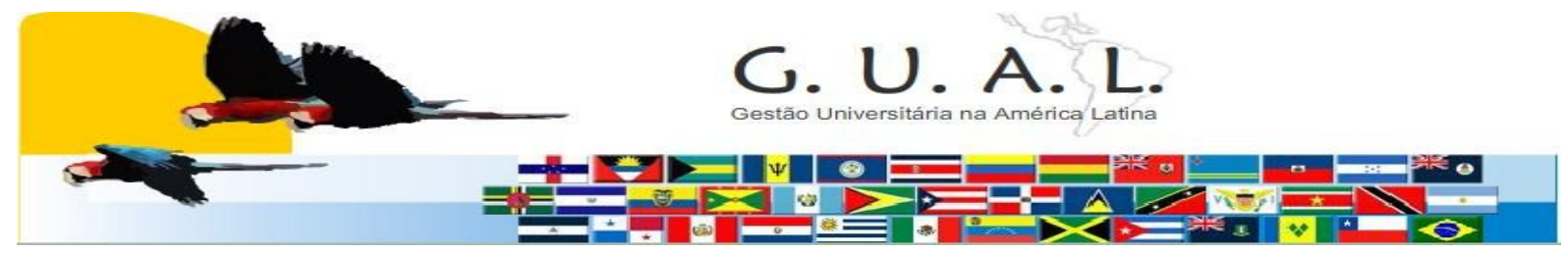

ISSN 1983-4535

\title{
STUDENT'S AUTONOMY IN DISTANCE EDUCATION: THE CASE OF THE DISTANCE ADMINISTRATION COURSE OF UFSC
}

Alessandra de Linhares Jacobsen, Doutora Universidade Federal de Santa Catarina - UFSC oajac@newsite.com.br

Maurício Fernandes Pereira, Doutor Universidade Federal de Santa Catarina - UFSC mpereira@cse.ufsc.br

Marcos Baptista Lopez Dalmau, Doutor Universidade Federal de Santa Catarina - UFSC dalmau@cse.ufsc.br

\author{
Rogério da Silva Nunes, Doutor \\ Universidade Federal de Santa Catarina - UFSC \\ rogerionunes@cse.ufsc.br
}

\author{
Rudimar Antunes da Rocha, Doutor \\ Universidade Federal de Santa Catarina-UFSC \\ rrudimar@cse.ufsc.br
}

\author{
Isaias Scalabrin Bianchi, Bacharel \\ Universidade Federal de Santa Catarina - UFSC \\ isaiasbianchi@hotmail.com
}

\begin{abstract}
The present paper intends to analyze how the Distance Administration Course of the Federal University of Santa Catarina (UFSC) manages the autonomy given to their students because of the system education's characteristics. This is realized through a bibliographic, qualitative and descriptive research, and through a case study, occurred from October of 2010 to June of 2011. The nom-probabilistic sample was chosen using the accessibility and typification rules and it is composed by the Department Chief (CAD), the Course Coordinator, and by 3 members of the Planning, Organizing and Execution Commission of the Course. The primary data were obtained from nom-structured interviews and from participant observation. The Distance Course shows positive results at the implementation of the independent learning, but there are also some fragilities that affect the student's autonomy in the technologies and in the behavior scope.
\end{abstract}

Keywords: Student autonomy. Distance education. Education Management. 